Research Article

\title{
Concern between medication non-adherence and diabetes associated depression
}

\author{
Krishnan Vengadaragava Chary ${ }^{1}$, Porchelvan Swaminathan ${ }^{2}$
}

\begin{abstract}
${ }^{1}$ Department of Pharmacology, Saveetha Medical College, Chennai, India, ${ }^{2}$ Department of Community Medicine, Saveetha Medical College, Chennai, India

Received: 13 February 2016 Revised: 15 February 2016 Accepted: 29 February 2016

\author{
*Correspondence to: \\ Dr. Krishnan Vengadaragava \\ Chary, \\ Email: doctorkrishforu@ \\ gmail.com
}

Copyright: (c) the author(s), publisher and licensee Medip Academy. This is an openaccess article distributed under the terms of the Creative Commons Attribution NonCommercial License, which permits unrestricted noncommercial use, distribution, and reproduction in any medium, provided the original work is properly cited.

\begin{abstract}
Background: Diabetes mellitus is one of the health disorders that acquire mankind immensely. An ominous twin of diabetes mellitus is diabetes associated depression which is often unrecognised in routine diabetic care. The objective of this study was to find the prevalence and correlation between medication adherence and diabetes associated depression.

Methods: It is a conducted as cross sectional study using Morisky medication adherence scale to evaluate treatment adherence of type II diabetes mellitus. Patient health questionnaire-9 was used to scale the level of depression among our study subjects. Correlation between measures of treatment non adherence and level of depression was elucidated.

Results: Out of 250 patients, $167(66.8 \%)$ (Males -103, Females-64) and 83 (33.2\%) (Males-31, Females-52) subjects has medium \& low adherence to medication with an average score 6.8 and 4.2 respectively. Total prevalence of depression among diabetics in our study is $41.1 \%$ (males-19.2\%, females $21.9 \%$ ). Percentage of patients found to have minor depression was $22.3 \%$ and $18.8 \%$ of depressive subjects falls under major depression category according to PHQ-9 questionnaire with average score of 8.6 for minor depression and 11.9 for major depression. Positive correlation is seen between medication non adherence and diabetes associated depression (Low adherence \& Major depression -0.85, Medium adherence \&Minor depression -0.79).

Conclusions: Unnoticed depression among diabetic individuals reduces treatment adherence and must be addressed in any patient showing poor response to the treatment. Improving treatment adherence helps to combat diabetes as well as depression.
\end{abstract}

Keywords: Diabetes associated depression, Diabetes education, Medication adherence

\section{INTRODUCTION}

In the era of epidemiologic transition, diabetes mellitus is one of the health disorders that acquire mankind immensely. There is no plummet in the prevalence of diabetes; India is expected to harbour seventy millions of diabetes patients by 2030. Considerable level of illiteracy, hindered access to health care, low socioeconomic status perpetuates the complexity seen with diabetes mellitus management. ${ }^{1,2}$ Among various barriers that are studied to overcome the diabetes pandemic, non-adherence to medication is evident and prevails widely in our population. ${ }^{3}$ In General, medication adherence is defined as the patient's conformance with the provider's recommendation with respect to timing, dosage, and frequency of medication-taking during the prescribed length of time. ${ }^{4}$ Longer duration of treatment, unaffordablity, lack of awareness and poor self-care are some of the common, well known factors that culminates in medication non-adherence of diabetes mellitus. ${ }^{5}$

An ominous twin of diabetes mellitus is diabetes associated depression which is often unrecognised in routine diabetic care. The association is postulated as 
'bidirectional', diabetes is having significant impact on determinants of depression and vice versa. There are few consensuses that give us an input, diabetes patients with depression are reluctant to adhere with their treatment and hence has constant high blood glucose level. Biological plausibility is also explored between hyperglycaemia and accentuation of depression. ${ }^{6,7}$ Studies has suggested that diabetes associated depressive patient's neglects not only their anti-diabetes medications, they tend to tend express less adherence to treatment of the co morbid conditions like hypertension and dyslipidemia. ${ }^{8,9}$ Amidst other studies done individually on medication adherence and depression determinants on diabetes patients, we conducted a cross sectional study to correlate the level of medication adherence and depression with an eagle eye view.

\section{METHODS}

\section{Study permission}

This study was conducted by department of Pharmacology in collaboration with internal e medicine of tertiary care teaching hospital. Study protocol was approved by our institutional ethics committee (ECR/724/Inst/TN/2015) and approved by Indian council of medical research (ICMR).

\section{Study questionnaire}

Adherence to medication was assessed using Morisky medication adherence scale (MMAS-8). This is a validated tool and found to be satisfactory to assess treatment adherence. Depression assessment was done using patient health questionnaire ${ }^{9}$ which is validated and standard questionnaire, used to assess diabetes associated depression by various research organisations including Indian council of medical research. This questionnaire has overall accuracy of $85 \%$, sensitivity $75 \%$ and specificity $90 \%$.

\section{Sample size determination}

Sample size was determined by assuming the average prevalence of depression among diabetes patients, 0.28 , power $80 \%$ and alpha error $5 \%$ and rounded off with respect to study duration. Consecutive two hundred and fifty patients were included for the study.

\section{Study procedure}

Questionnaire was read out by the investigator to the diabetic patients who read the information sheet and gave consent to participate in our study. Demographic details, treatment profile of diabetes and other co morbid conditions were noted. Anthropometry assessment was carried out on the study day. Body height was measured using stadiometer, height (to the nearest $0.1 \mathrm{~cm}$ ) was taken. A digital scale, with an accuracy of $\pm 100 \mathrm{~g}$, was used to measure body weight $(\mathrm{BW})$. The readings were repeated three times and the mean was calculated. The waist circumference (WC) was measured in a horizontal plane, midway between the inferior margin of the ribs and the superior border of the iliac crest. Body mass index $(\mathrm{BMI})\left(\mathrm{kg} / \mathrm{m}^{2}\right)$ was calculated by dividing weight (in kilograms) by the square of height (in meters). In the end, all our participants were informed the significance of treatment adherence by the investigator.

\section{RESULTS}

Data entry and analysis was done MS Excel Macro and SPSS (Stastical package for Social Sciences) Version 17. Chi square test and Spearman correlation test were employed to elucidate significance and correlation between variables respectively. Out of 250 patients enrolled for our study, number of males were $113(45.2 \%)$ and $137(54.8 \%)$ females. Mean duration of diabetes is 11.6 years and HbA1c 8.9. The most common co morbidity present in our study population was hypertension $54 \%$, followed by dysplidemia $48.2 \%$. Baseline characteristics of the study subjects are depicted in table 1.

Table 1: Baseline characteristics of our study subjects.

\begin{tabular}{|llll|}
\hline Baseline Characteristics & Overall $($ Mean \pm SD) & Number of males $(\mathbf{n}-113)$ & Number of females (n-137) \\
\hline Age (in years ) & $66.2 \pm 9.8$ & $59.01 \pm 4.5$ & $64.02 \pm 3.4$ \\
\hline Duration of diabetes (in years) & $11.6 \pm 2.1$ & $10.8 \pm 3.4$ & $9.8 \pm 2.3$ \\
\hline Body mass index $\left(\mathrm{Kg} / \mathrm{m}^{2}\right)$ & $25.1 \pm 1.4$ & $25.7 \pm 1.78$ & $24.3 \pm 0.76$ \\
\hline Literacy rate & $63.00 \%$ & $66.26 \%$ & $60.01 \%$ \\
\hline Income & Rs .8815/-INR & Rs. $10.031 /-$ INR & Rs. 7600/-INR \\
\hline Residence, urban vs. rural & Urban 54.4\% & $52.10 \%$ & $50.98 \%$ \\
\cline { 2 - 4 } & Rural 45.6\% & $47.90 \%$ & $49.02 \%$ \\
\hline HbA1c value & $8.9 \pm 0.9$ & $8.2 \pm 1.2$ & $9.7 \pm 1.1$ \\
\hline Using oral hypoglycaemic agents alone & $165(66 \%)$ & 73 & 92 \\
\hline Using oral hypoglycaemic with insulin & $85(34 \%)$ & 48 & 37 \\
\hline $\begin{array}{l}\text { Diagnosed with coexisting } \\
\text { hypertension }\end{array}$ & $135(54 \%)$ & 61 & 74 \\
\hline $\begin{array}{l}\text { Diagnosed with coexisting } \\
\text { dyslipidemia }\end{array}$ & $123(48.2 \%)$ & 67 & 66 \\
\hline
\end{tabular}


Table 2: Variables showing significant association with medication non adherence and diabetes associated depression.

\begin{tabular}{|lllll|}
\hline Variables & $\begin{array}{l}\text { MMAS } \\
\text { score }\end{array}$ & $\begin{array}{l}\text { Odds ratio } \\
(\mathbf{9 5 \%} \text { CI })\end{array}$ & $\begin{array}{l}\text { PHQ-9 } \\
\text { score }\end{array}$ & $\begin{array}{l}\text { Odds ratio } \\
(\mathbf{9 5 \%} \text { CI })\end{array}$ \\
\hline Gender (Male vs. Females) & 3.7 & $\mathrm{p}-0.041,1.17(1.11-1.63)$ & 9.12 & $\mathrm{p}-0.05,1.14(1.02-1.34)$ \\
\hline $\begin{array}{l}\text { Duration of diabetes } \\
(<5 \text { years Vs. }>5 \text { years) }\end{array}$ & 4.6 & $\mathrm{p}-0.002,1.89(1.11-1.92)$ & & \\
\hline Literacy (Illiterate Vs literate) & 4.1 & $\mathrm{p}-0.028,2.3(1.76-2.59)$ & 7.95 & $\mathrm{p}-0.032,1.67(1.21-1.89)$ \\
\hline Income $(<5000$ or $>5000)$ per month & 5.9 & $\mathrm{p}-0.015,1.54(1.33-1.75)$ & 8.32 & $\mathrm{p}-0.021,1.33(1.11-1.78)$ \\
\hline BMI $\left(<25\right.$ or $\left.>25 \mathrm{~kg} / \mathrm{m}^{2}\right)$ & 6.8 & $\mathrm{p}-0.052,1.76(1.32-1.92)$ & 7.81 & $\mathrm{p}-0.05,1.32(1.02-1.56)$ \\
\hline Use of oral drugs only & 6.7 & $\mathrm{p}-0.031,1.13(1.02-1.45)$ & 6.81 & $\mathrm{p}-0.05,1.12(1.09-1.38)$ \\
\hline HbA1c $(<7$ or $>7)$ & 3.7 & $\mathrm{p}-0.033,1.43(1.21-1.63)$ & 9.61 & $\mathrm{p}-0.023,1.12(1.01-1.24)$ \\
\hline Use of Insulin plus oral agents & 4.6 & $\mathrm{p}-0.027,1.13(1.09-1.45)$ & 10.09 & $\mathrm{p}-001,1.22(1.12-142)$ \\
\hline Co morbidity (present vs absent) & 4.3 & $\mathrm{p}-0.022,1.78(1.44-1.98)$ & 10.79 & $\mathrm{p}-0.001,1.44(114-1.78)$ \\
\hline
\end{tabular}

10-14 major depression

Table 3: Correlation between medication adherence and diabetes associated depression.

\begin{tabular}{|llll|}
\hline No & $\begin{array}{l}\text { Adherence } \\
\text { Range }\end{array}$ & $\begin{array}{l}\text { Average } \\
\text { depression } \\
\text { score }\end{array}$ & $\begin{array}{l}\text { Correlation } \\
\text { coefficient }\end{array}$ \\
\hline 1 & $<6$ & 11.7 & 0.85 \\
\hline 2 & $6-8$ & 9.3 & 0.79 \\
\hline 3 & 8 & 5.2 & 0.72 \\
\hline
\end{tabular}

MMAS -8 Score 8 -High Adherence; 6-8 -Medium adherence; $<6$-Low adherence; PHQ- 9 Score 5-9 Minor depression; PHQ9 Score 10-14 major depression

Number of subjects with medium adherence is 167 (66.8\%) (males-103, females-64) and 83 (33.2\%) (males31 , females-52) subjects has low adherence to medication with an average score 6.8 and 4.2 respectively. Total prevalence of depression among diabetics in our study is $41.1 \%$ (males-19.2\%, females $21.9 \%$ ). The percentage of patients found to have minor depression was $22.3 \%$ and $18.8 \%$ of depressive subjects falls under major depression category according to PHQ-9 questionnaire with average score of 8.6 for minor depression and 11.9 for major depression. Binary logistic regression values between variables and average adherence score $\&$ depression score is shown in Table 2.

\section{DISCUSSION}

Escalating number of chronic illness mandates the daily intake one or more medicines by global population. Medication not continued as prescribed in about $50 \%$ of cases and never filled in 20-30\% of cases. Medication non adherence results in poor quality of life, decreased life expectancy and affects health economy, direct cost expenditure rise up to 300 million US dollars. Nonadherence causes $\sim 30 \%$ to $50 \%$ of treatment failures and 125,000 deaths annually. ${ }^{10,11}$
In our study, about sixty six percent of subjects has medium to low adherence towards their anti-diabetes medicines. A study conducted by Arulmozhi et al showed fifty percent of diabetic population has low adherence which is slightly less than our findings. ${ }^{12}$ Rates of medication adherence drops as years pass on, our study subjects exhibit poor adherence with increase in mean duration of diabetes and similar trend is reported by Mukherjee et al in 2013. In our study females subjects were found be to less compliant with their treatment when compared with males which is in contrast to the aforesaid studies. ${ }^{13}$ Low literacy rate, less income, insulin intake, high BMI and presence of co morbid conditions affects medication adherence considerably. ${ }^{14}$

Findings focussed regarding presence of coexisting diabetes associated depression revealed about forty one percent of diabetic population is affected with depression. In a report by Indian council of medical research showed similar values of prevalence, however the results are discordant with respect to mean duration and use of insulin with respect to us. In our study, longer the duration of diabetes, higher HbA1c values and intake of insulin associated with more score on depression scale. $^{15,16}$

In our study, positive correlation is established between levels of medication adherence and scale of depression in diabetic population. The correlation is also supported by experimental and clinical studies which are discussed here. Diabetes associated depression contributes significantly in medication non adherence and poor diabetic control increases the risk of depression, this vicious relationship is supported by biological certain recent biological findings. Serotonergic system is affected by uncontrolled hyperglycaemias, the levels of free tryptophan decreases and tryptophan hydroxylase enzyme which is responsible for conversion tryptophan to 5Hydroxytrptamine (5-HT) is found dysfunctional among diabetes population. Low levels of serotonergic system 
function pave the possible link between diabetes and depression. ${ }^{17,18}$ In an experimental study, streptozocin induced diabetic rats express less number of 5-HT1A receptors in prefrontal cortex which increases risk of depression. Genetic links are also established between diabetes associated depressions, the polymorphisms in the lower expressing allele of the 5-HTT gene 5' promoter region increases depression risk. Down regulation of insulin receptors in and worsening of insulin resistance is implicated in patients with significant depression. ${ }^{19-26}$ There are well documented clinical studies that proved diabetes associated depressive patients do not adhere with their treatment and succumb to higher macrovasclar complication and higher mortality rate. Psychological well-being and health outcome improves when treatment

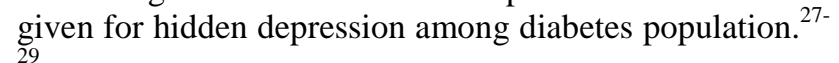

From our study we suggest along with the steps taken to improve medication adherence so far, patients with poor control of diabetes must be assessed for treatment adherence and presence of unsaid depression. Empathy and good communication from physician increases confidence and medication adherence among patients. We suggest also screening for depression is a must need in routine diabetic care. Diabetic counselling by trained educators improves treatment adherence as well as depression. $^{30,31}$

\section{CONCLUSION}

Unnoticed depression among diabetic individuals reduces treatment adherence and must be addressed in any patient showing poor response to the treatment. Improving treatment adherence helps to combat diabetes as well as depression.

\section{ACKNOWLEDGEMENT}

We thank ICMR for supporting our project under ICMR STS scheme.

\section{Funding: By ICMR for our project under ICMR STS scheme}

Conflict of interest: None declared

Ethical approval: The study was approved by the Institutional Ethics Committee

\section{REFERENCES}

1. International diabetes federation: diabetes atlas 2000. Brussels, international diabetes federation, 2000.

2. Ramachandran A, Snehalatha C, Kapur A, Vijay V, Mohan V, Das AK et al. Diabetes epidemiology study group in India (DESI). High prevalence of diabetes and impaired glucose tolerance in India: National urban diabetes survey. Diabetologia. 2001;44:1094-10.
3. Gelaw BK, Mohammed A, Tegegne GT, Defersha $\mathrm{AD}$, Fromsa M, Tadesse E et al. Non-adherence and contributing factors among ambulatory patients with antidiabetic medications in Adama Referral Hospital. J Diabet Res. 2014;2014:617041.

4. Medication Adherence Interventions: Comparative Effectiveness. Available at: http://www.effectivehealthcare.ahrq.gov/ehc/product s/296/1248/EvidenceReport208_CQGMedAdherenc e_FinalReport_20120905.pdf. Accessed on 15 January, 2016.

5. Riaz M, Basit A, Fawwad A, Yakoob Ahmedani M, Ali Rizvi Z. Factors associated with non-adherence to insulin in patients with type 1 diabetes. Pakistan J Med Sci. 2014;30(2):233-9.

6. Katon WJ. The Comorbidity of diabetes mellitus and depression. The American J Med. 2008;121(1):8-15.

7. Gonzalez JS, Peyrot M, McCarl LA, Collins EM, Serpa L, Mimiaga MJ et al. Depression and diabetes treatment non-adherence: a meta-analysis. Diabet Care. 2008;31(12):2398-403.

8. Leone T, Coast E, Narayanan S, de Graft Aikins A. Diabetes and depression comorbidity and socioeconomic status in low and middle income countries (LMICs): a mapping of the evidence. Global Health. 2012;11:8-39.

9. Lustman PJ, Anderson RJ, Freedland KE, de Groot M, Carney RM, Clouse RE. Depression and poor glycemic control: a meta-analytic review of the literature. Diabetes Care. 2000;23:934-42.

10. Goldman DP, Joyce GF, Zheng Y. Prescription drug cost sharing: associations with medication and medical utilization and spending and health. JAMA. 2007;298:61-9.

11. George J, Shalansky SJ. Predictors of refill nonadherence in patients with heart failure. British $\mathbf{J}$ Clin Pharmacol. 2007;63(4):488-93.

12. SA, TM. Self-care and medication adherence among type 2 diabetics in Puducherry, Southern India: a hospital based study. J Clin Diagn Res. 2014;8(4):UC01-3.

13. Mukherjee S, Sharmasarkar B, Das KK, Bhattacharyya A, Deb A. Compliance to antidiabetic drugs: observations from the diabetic clinic of a medical college in Kolkata, India. J Clin Diagn Res. 2013;7(4):661-5.

14. Santhanakrishnan I, Lakshminarayanan S, Kar SS. Factors affecting compliance to management of diabetes in urban health center of a tertiary care teaching hospital of south India. J Natur Sci Biol Med. 2014;5(2):365-8.

15. Raval A, Dhanaraj E, Bhansali A, Grover S, Tiwari P. Prevalence \& determinants of depression in type 2 diabetes patients in a tertiary care centre. Indian $\mathbf{J}$ Med Res. 2010;132(8):195-200.

16. Roy T, Lloyd CE. Epidemiology of depression and diabetes: A 3. Systematic review. J Affect Disord. 2012;142:8-21.

17. Anderson RJ, Freedland KE, Clouse RE, Lustman PJ. The prevalence of comorbid depression in adults 
with diabetes: a meta-analysis. Diabetes Care 2001;24:1069-78.

18. Visakh P, Deepali G, Prateek K, Radhakrishnan M. Diabetes-associated depression: the serotonergic system as a novel multifunctional target. 2015;47(1):4-10.

19. Dou JT, Chen M, Dufour F, Alkon DL, Zhao WQ. Insulin receptor signaling in long-term memory consolidation following spatial learning. Learn Mem. 2005;12:646-55.

20. Smith GS, Kramer E, Hermann C, Ma Y, Dhawan $\mathrm{V}$, Chaly $\mathrm{T}$ et al. Serotonin modulation of cerebral glucose metabolism in depressed older adults. Biol Psychiatry. 2009;66:259-66.

21. Wilhelm K, Gillis I, Reddy J, Mitchell PB, Campbell L, Dobson-Stone C et al. Association between serotonin transporter promoter polymorphisms and psychological distress in a diabetic population. Psychiatry Res. 2012;200:3438.

22. Zalsman G, Huang YY, Oquendo MA, Burke AK, $\mathrm{Hu} \mathrm{XZ}$, Brent DA et al. Association of a triallelic serotonin transporter gene promoter region (5HTTLPR) polymorphism with stressful life events and severity of depression. Am J Psychiatry. 2006;163:1588-93.

23. Manjarrez-Gutiérrez G, Herrera-Márquez JR, Molina-Hernández A, Bueno-Santoyo S, GonzálezRamírez M, Hernández J. Changes in cerebral serotonin synthesis induced by insulin-dependent diabetes mellitus. Rev Invest Clin. 1999;51:293-302.

24. Herrera R, Manjarrez G, Hernandez J. Inhibition and kinetic changes of brain tryptophan-5-hydroxylase during insulin-dependent diabetes mellitus in the rat. Nutr Neurosci. 2005;8:57-62.

25. Miyata S, Hirano S, Kamei J. Diabetes attenuates the antidepressant-like effect mediated by the activation of 5-HT1A receptor in the mouse tail suspension test. Neuropsychopharmacol. 2004;29:461-9.

26. Sandrini M, Vitale G, Vergoni AV, Ottani A, Bertolini A. Streptozotocin-induced diabetes provokes changes in serotonin concentration and on 5-HT1A and 5-HT2 receptors in the rat brain. Life Sci. 1997;60:1393-7.

27. Kinder LS, Katon WJ, Ludman E, Russo J, Simon $\mathrm{G}$, Lin EHB et al. Improving depression care in patients with diabetes and multiple complications. J Gen Intern Med. 2006;21(10):1036-41.

28. Lin EHB, Rutter CM, Katon W, Heckbert SR, Ciechanowski P, Oliver MM et al. Depression and advanced complications of diabetes: a prospective cohort study. Diabetes Care. 2010;33(2):264-9.

29. Lin EHB, Heckbert SR, Rutter CM, Katon WJ, Ciechanowski P, Ludman EJ et al. Depression and increased mortality in diabetes: unexpected causes of death. Ann Family Med. 2009;7(5):414-21.

30. Haynes RB, Ackloo E, Sahota N, McDonald HP, Yao X. Interventions for enhancing medication adherence. Cochrane Database Syst Rev. 2008;(2):CD000011.

31. Chen B, Zhang X, Xu X, Xiaofeng Lv, Lu Yao, Xu Huang et al. Diabetes education improves depressive state in newly diagnosed patients with type 2 diabetes. Pakistan J Med Sci. 2013;29(5):1147-52.

Cite this article as: Chary KV, Swaminathan $\mathrm{P}$. Concern between medication non-adherence and diabetes associated depression. Int J Basic Clin Pharmacol 2016;5:523-7. 